\title{
Toward a Field Model of the Self
}

What an abyss of uncertainty, whenever the mind feels overtaken by itself; when it, the seeker, is at the same time the dark region through which it must go seeking and where all equipment will avail it nothing.

- Marcel Proust

Remembrance of Things Past

When I find myself, I always find that self coexisting with something facing that self, something in front of it and opposing it; the world or the circumstance, the surroundings. It is certain that this something does not exist by itself, apart from me. . . . But neither do I ever exist alone and within myself; my existing is coexisting with that which is not I. Reality, then, is this interdependence and coexistence.

- José Ortega y Gasset

Some Lessons in Metaphysics

It is, perhaps, a suggestive irony that we live in an age characterized by both an obsessive concern for the ego or individual self and a denial that there is any such reality. The first characteristic is manifest in the charges that contemporary experience is best described as narcissistic, or that the present generation is the "me" generation, or that ours is a hedonistic culture in which self-satisfaction is the dominant if not exclusive value. The denials of the ego or the individual self come from the more intellectually sophisticated segments of the community, taking such various forms as Buddhist "no-self" doctrines and structuralist and deconstructionist movements. Both perspectives have validity not only as descriptions but, more important, as expressions of significant human concerns, neither of which can be ignored in any effort to construct a viable view of the human self. Yet the sharp contrast and conflict between these apparently opposed perspectives, combined with the multiplicity of technical problems involved, should temper any hopes for the emergence in the near future of anything approaching a definitive doctrine of the self. "Everything one says about the self," as Ralph Harper perceptively notes, "should be regarded as tentative, born in swirling mists of conflict and self-conflict." Such a cautionary warning is 
even more necessary in an effort whose deliberate purpose is the construction of a model of the self that is open to the possibility of immortality or, as a bare minimum, does not conclusively exclude a belief in immortality or resurrection.

\section{CONCERNING A "FIELD MODEL" FOR THE "SELF"}

My modest but still relatively ambitious aim here is not to present a "theory" of the self, or even a "model" in the more technical and developed sense of these terms, but rather to describe the broad outlines of what a "fieldself" ought to involve. The development and detailed filling-out of this sketch would necessitate relating and applying it to a variety of disciplines and areas of human experience. For example, it would be necessary to relate the constructed model to data and theories in physics, chemistry, biology, psychology, and sociology. Further, one would have to show that this model is suggestive and illuminating as regards moral, political, and religious questions. Most important would be to indicate how it might allow for fruitful transactions between and among those various disciplines and distinct spheres of experience. As with any theory or model, therefore, a field model of the self would have to be tested and then developed, modified, or rejected in terms of its experiential fruits. This testing, of course, is really a collective, long-run testing and is not to be realized by any individual or restricted group of individuals. Indeed, within the pragmatic frame, the most that could be hoped for would be a relatively complete confirmation in the form of an ever expanding and enriching dialectic between cumulating diverse data and the relatively stable but ever developing fields that constitute the self. The open-ended character of such an endeavor is in keeping with the kind of world already described.

The most that can be claimed for what follows is that it suggests a direction and something of what might be achieved by the utilization of the "fields" metaphor in relation to the human self. As such, it might be designated an ontological or metaphysical speculation which though distinct from must also be consistent with both empirical and phenomenological inquiries. Needless to say, such a speculation neither supplants nor substitutes for either of these activities. Finally, a particular concern of this speculation will be to open up ethical and religious possibilities and indicate how these activities might be justified.

Even in this rather vague, initiating stage of speculative inquiry, however, one must do more than advance airy generalizations or gratuitous hypotheses. Hence, the model constructed must be "reasonably" coherent and consistent; that is, it must not involve gross illogicalities, and it must not be in conflict with well-attested and firmly grounded data from the various intellectual disciplines. Further, it must flow from, be consistent with, and help develop the processive-relational world that is being presupposed. In sum, 
in keeping with the assumed pragmatic perspective, this model of the self must do-or at least allow for the possibility of doing - the following:

1. preserve individuality without falling into atomistic individualism or egocentric isolationism;

2. account for change, growth, and development;

3. account for a range and diversity of relations;

4. account for continuity, identity, sameness, and difference;

5. account for a variety of structures or dynamic systems such as the psychological, personal, historical, cultural, social, and religious;

6. indicate how individuals both make and are made by language, history, art, science, religion, and other institutions;

7. allow for creative participation in wider processes or fields;

8. allow for radical transformation without obliteration or absorption into another reality or process.

Now what, it might be asked, does such a self have to do with immortality or resurrection? The claim made is that such a self is not necessarily prohibited from continuing its reality and activities beyond the parameters of what is customarily described as "this world." At the same time, any concern for immortality must be shown to deepen and intensify rather than diminish participation in the "here and now." Hence, given the kind of world or reality already described, continuance in a new life is not in itself in conflict with such participation. The kind of world, therefore, in which personal immortality is a possibility would be a richer and more variegated world than one from which it is definitively excluded.

\section{SELF AS "FIELDS WITHIN FIELDS ..."}

Let me try to describe this self explicitly as "fields within fields. . . ." I want to suggest that a self is composed of submicroscopic, microscopic, macroscopic, and ultramacroscopic fields. Without any pretense to an exhaustive enumeration, we can list the following fields as continuous and overlapping but nevertheless distinct. Among the submicroscopic fields would be found atoms, electrons, neutrons, protons, and whatever may be the latest particles designated by the physicists. Cells and molecules are, of course, microscopic fields, themselves constructed of the submicroscopic fields just mentioned. We enter the realm of macroscopic fields when we focus on organs such as the brain, heart, and liver as well as muscles and bones. Again, these macroscopic fields are constituted by distinctive cell fields and in turn constitute the individual organism, itself a macroscopic field. At this point it might be useful, to distinguish between "inner" and "outer" macroscopic fields that enter into the reality of the individual organism. Those just listed would, of course, be "inner"; among the "outer" would be atmospheric and environmental fields such as oxygen, hydrogen, water, foodstuffs, and other organisms. We move into the realm of ultramacroscopic fields when we locate the multiplicity of macroscopic fields 
within the earth field. This field in turn is located within the solar field, which is within the galactic field, which is within the universe field, which is within ....

To this point the description of the self is most uncontroversial, but it is also most incomplete: uncontroversial because I have included only those fields whose "observability" and "reality" evoke a high level of consensus; incomplete because I have not included those fields that most distinguish human selves from other organic fields. When we focus on any human organism, we are compelled to acknowledge additional fields: the unconscious, the dispositional, the conceptual, the social, the personal, the cultural, the religious, the historical, and the like. I have deliberately avoided labeling these fields as physical and psychological or mental, in order to avoid any ontological dualism. It may be useful later to reintroduce such distinctions as functional categories; for the moment, however, I wish simply to stress that all these fields are real and interdependent, and are involved in the structure of the self. Any reductionism that would give an ontological priority to any field or group of fields is unacceptable. This is not to say that all these fields must have the same degree of intimacy in relation to the self. Whether they are all inseparable from the reality of the self is a speculative question that must be addressed later.

For the moment, it will suffice to describe the various aspects characterizing the self from the field perspective. When James speaks of the self as "all shades and no boundaries," he is rejecting any encapsulated self-any self enclosed within the envelope of the skin or in some inner ego or mind. ${ }^{2}$ As John Herman Randall, Jr., has noted: "It is indeed amazing that students of man should ever have convinced themselves that the mechanisms of human behavior are located exclusively within the skin of the organism, or within a private and subjective 'mind,' in view of the obvious fact that everything that distinguishes man from the other animals is a common and social possession." 3

It is this image of the self as radiating "outward" and overlapping and being overlapped by numerous other fields that must constantly be kept in mind as we focus our attention on particular aspects. Initially and tentatively, therefore, let us understand "the self" 4 as the widest and most inclusive field in relation to the plurality of subfields mentioned earlier. Of course, it is wide and inclusive only in relation to these subfields, because in relation to suprafields it is itself a subfield. Whether this "field-self" is a postulate and what grounds there are, if any, for such a postulate are questions that can be addressed only after we have attempted to describe the distinguishing characteristics of this self.

\section{THE FIELD-SELF AS NONDUALISTIC}

As the history of philosophy repeatedly attests, any shift in perspective or any new idea emerges and can be understood only in reference to the perspective or idea it is endeavoring to replace. The Introduction notes that a 
process view of reality rejects any metaphysical or ontological dualism whereby reality is bifurcated into the changing and the unchanging, the temporal and the eternal. Similarly, a field view of the self resists such dualisms as mind-body, psychical-physical, spiritual-material, subjective-objective, insofar as these terms refer to essentially different orders of reality. ${ }^{5}$ This is not to suggest that these distinctions have no meaning or utility, or that there is no difference between, for example, thinking and walking, or willing and running. The question is how to account for such differences, and a nondualistic view denies that they must be accounted for by dichotomizing the self and the world in such a manner as to locate one set of activities in a realm designated spiritual and the other set in a realm designated material. More positively, the field view suggested here will attempt to account for these real differences and distinctions in terms of functions and processes, so that while rejecting various modes of ontological dualism, it will not hesitate to affirm a variety of functional dualisms.

Of more immediate concern is whether, given the stated aim of this essay, it will be possible to avoid attributing features to the self that render this model vulnerable to some of the objections raised against dualism. ${ }^{6}$ Since I intend to describe or construct a model that does not exclude the possibility of the selfs continuing and participating in a life beyond the parameters of what we customarily call "this world," some will see such effort as a "bad faith" attempt to escape contemporary arguments against dualism. Hence, let me say immediately that if any view of the self that allows it a reality and life not confined to the explicitly localizable and identifiable parameters of "this world" is called "dualism," then of course my view must be so designated. While I believe such a definition unjustifably restrictive, what is important in the final analysis is not the particular label but whether persuasive evidence and arguments, as well as plausible speculations, can be marshaled in support of a field-self.

\section{PRAGMATIC OBJECTIONS TO DUALISM}

Whatever the differences between Greek, medieval, and modern expressions of dualism, they all affirm the reality of an immaterial substance or substantial principle. Whether designated mind, intellect, or soul, this principle or entity is made of a kind of being and belongs to an order of reality essentially different from the body to which it is joined-mysteriously or naturally. The nonexistence of such a principle cannot, of course, be proved, and pragmatism makes no such claim. "Our reasonings," James conceded, "have not established the nonexistence of the Soul; they have only proved its superfluity for scientific purposes" (PP, I:332). We miss the thrust and bite of James's criticism if we understand "scientific" in a narrow positivistic sense, which would leave open the possibility of accounting for the soul by a "philosophical" method. It is the uselessness of the "soul" for the purposes of the broadest intellectual inquiry that leads the pragmatist to exclude it 
from any explanatory effort. James expresses this view: "My final conclusion, then, about the substantial Soul is that it explains nothing and guarantees nothing" ( $P P, \mathrm{I}: 331)$. Many years later, with his customary philosophic generosity, James conceded that "some day, indeed, souls may get their innings again in philosophy," but this will happen "only when someone has found in the term a pragmatic significance that has hitherto eluded observation" (PU, 95-96). James is, perhaps, being unduly gracious here, since "souls" with "pragmatic significance" would not be the same "souls" as those being rejected.

Now a defender of a soul theory would undoubtedly reply that the soul is posited precisely because of its explanatory power and pragmatic significance. The soul serves as a rational explanation of why an organic being has unity, identity, continuity, and individuality. The pragmatist, as we shall see, must indeed account for these characteristics of the self and give some indication of how this might be done without positing a substantial soul. Even apart from these features, however, it might be argued that great pragmatic significance attaches to an immaterial substance or soul insofar as its simplicity and incorruptibility guarantees its natural immortality. James does not deny that such a soul would be immortal; his claim is that the immortality would be such that most people would not desire it.

The Soul, however, when closely scrutinized, guarantees no immortality of a sort we care for. The enjoyment of the atom-like simplicity of their substance in saecula saeculorum would not to most people seem a consummation devoutly to be wished. The substance must give rise to a stream of consciousness continuous with the present stream, in order to arouse our hope, but of this the mere persistence of the substance per se offers no guarantee. (PP, I:330)

I will explore this text more fully in presenting a substantive self as a more fruitful model than a substantial soul. For the moment, let it serve to indicate why, from a pragmatic perspective, the substantial soul is considered devoid of significant experiential fruits.

The oldest, most persistent, and strongest argument for the existence of an immaterial substance stems from that intellectual activity which distinguishes human beings from other conscious beings. The argument takes a variety of forms, but as Randall describes it, the contention is basically that since humans are able to grasp universals which are simple and immaterial, they "must 'have' or 'possess' a 'single unextended immaterial spiritual principle' [called 'Mind'] with which to do it!" (NHE, 218). Randall presents three major reasons why this argument does "not seem to present-day metaphysicians very fruitful."

The first reason is that to posit a distinct principle for every distinct activity would destroy the possibility of explanation and intelligibility: "Every distinguishable process of Nature would then have to be accomplished by a principle unique and proper to itself." Such an indefinite multiplication of 
principles would lead to intellectual chaos, rendering it impossible to "explain" any phenomenon. Randall asks us to imagine what physics would look like "had Nature been really so constituted that each of her distinguishable productions required a specifically different mechanism as its necessary condition!" (NHE, 218-19).

Randall's second reason for rejecting the characterization of "Mind" as an immaterial substance is that to do so is "to convert the operation of a 'power' into its own mechanism and conditions." The argument here is that merely to posit "mind" as the "power" to act "is to remain with a mere statement of the observed facts, without attempting any further analysis of the complex mechanisms involved." In other words, to attempt to explain thinking by saying we have the "power" to think is to say and explain nothing. Randall considers such a view analogous to the famous satirical example of Molière "of trying to 'explain' the observed action of opium upon the human organism as due to its 'dormitive powers'" (NHE, 219).

Randall's final objection is that construing "Mind" as a unique kind of substance makes the factors involved in thinking "wholly private and inaccessible" and thereby "obscures all the cultural and environmental factors which are in reality necessary conditions of any 'functioning mentally'" (NHE, 219-20). In sum, then, the objections raised by Randall, which accurately reflect the views of both James and Dewey, not only call attention to the emptiness of the substantial soul principle but, more important, emphasize that the positing of such a principle tends to divert energy from more concrete and fruitful avenues of investigation.

Dewey was particularly sensitive to what might be called the existential consequences of any ontological dualism. He notes how such a perspective leads to the extremes of both objectivism and subjectivism, which, though opposed, give impetus and justification one to the other. The location of the "objective" and the "subjective" in essentially different and discontinuous orders of reality results in reciprocal excesses. "An objectivism which ignores initiating and re-organizing desire and imagination will in the end only strengthen that other phase of subjectivism which consists in escape to the enjoyment of inward landscape." This ontological split inevitably leads to a split in philosophy whereby we have a "realistic" philosophy "for mathematics, physical science and the established social order; another, and opposed philosophy for the affairs of personal life" (EN, 241). Dewey goes on to say:

The objection to dualism is not just that it is a dualism, but that it forces upon us antithetical, non-convertible principles of formulation and interpretation. If there is a complete split in nature and experience then of course no ingenuity can explain it away; it must be accepted. But in case no such sharp division actually exists, the evils of supposing there is one are not confined to philosophical theory. Consequences within philosophy are of no great import. But philosophical dualism is but a formulated recognition of an impasse in life; an 
impotence in interaction, inability to make effective transition, limitation of power to regulate and thereby to understand. (EN, 241-42)

The years since Dewey wrote these words have hardly served to diminish the potentially disastrous consequences of dividing reality and human experience into two worlds having such basically different constitutions and touching and communicating with each other only indirectly, accidentally, and incidentally. As the allegedly "impersonal" and "objective" orders of science, technology, and society have grown to overwhelming proportions, there has emerged in response the passionate call for the recognition and practice of activities that flow from and depend almost totally upon allegedly "inner experience" or "personal faith" or "humanistic insight" or "religious revelation." At no time in history, perhaps, has there been a greater need to overcome the isolating opposition of these distinct "aspects" of reality and experience, and to create fruitful means and channels of transaction and communication. This, needless to say, is a formidable task that demands the fullest participation of a diversity of human beings bringing their distinctive experiences to bear upon this question. There will be no shortcuts and many deadends, as there are in any kind of experimental activity. As a minimum, however, an effort must be made to rid ourselves of that deeply ingrained prejudice that has converted distinct functions and processes, which flow into and overlap one another, into discontinuous realms of reality and experience.

\section{FIELD-SELF AND MATERIALISM}

There have been three metaphysical accounts, though with many variations, of reality and human beings. In addition to the dualism just discussed, there have been two forms of monism. Idealistic monism maintains that all reality is ultimately reducible to mind or is a mode or manifestation of mind or idea. Materialism, as the polar opposite of idealism, has insisted that all reality is reducible to matter-including mind, which is nothing but a mode or manifestation of matter. ${ }^{7}$ Where are we to locate field metaphysics? My suggestion is that while partaking of aspects of all three of these traditional views, field metaphysics is not reducible to or completely identifiable with any of them. Abstractly considered, a field model is indifferent to these three views and hence could quite easily be employed by any or all of them. Only after I have spelled out in more concrete detail a field model that I judge adequate will we be able to see what is shared and not shared with these other views. Yet inasmuch as both James and Dewey can be and have been read, at least in part, as materialists, a few preliminary words are in order. $^{8}$

The various expressions of contemporary materialisms are a long way from the relatively clear-cut materialism of Democritus, in which atoms of varying sizes and shapes alone were considered real and the apparent dif- 
ferences we experience due solely to the arrangement of these atoms. When the anthropology of Claude Lévi-Strauss and the history of Fernand Braudel are described as materialisms, it is evident that something much more subtle is at work. ${ }^{9}$ Fortunately, it is not the task of this essay to delineate the distinguishing features of these intellectual expressions. I need only indicate a few broad and relatively unrefined meanings of materialism to differentiate it from the field metaphysics that is here proposed.

Reductive materialism is the oldest and most unequivocal expression of materialism. Simply stated, it claims that everything real is reducible to whatever happens to be understood as "matter." Thus, however different things may appear, ultimate analysis reveals them to be nothing but the basic constituents of matter variously organized. This reductionist perspective is succinctly and explicitly expressed by a character in one of Stanislaw Lem's science fiction short stories.

Are not we as well, if you examine us physically, mechanistically, statistically, and meticulously, nothing but the miniscule capering of electron clouds? Positive and negative charges arranged in space? And is our existence not the result of subatomic collisions and the interplay of particles, though we ourselves perceive those molecular cartwheels as fear, longing, or meditation? And when you daydream, what transpires within your brain but the binary algebra of connecting and disconnecting circuits, the continual meandering of electrons? 10

Such a reductive materialism is subject to rather widespread criticism, ${ }^{11}$ and among its critics we can safely place pragmatism with its field metaphysics. We have already asserted that all fields or relational processes are real and that the task of inquiry is to discover the distinctive features of these fields and their relations and transactions without assigning metaphysical priority or exclusivity to any of them. Materialism, as Randall indicates,

illustrates where one gets when one does not take activities and processes as primary and irreducible subject-matter. A sound metaphysics would say, activities, operations, and processes "exist," and are effected by means of mechanisms distinguished as factors involved in those processes. "Materialism" locates the means and mechanisms involved; then by reductive analysis, holds that only these mechanisms can be said to "exist"-what they do does not "exist," but is merely something else. (NHE, 206) ${ }^{12}$

James raises what might be called an existential or moral objection to materialism:

A philosophy whose principle is so incommensurate with our most intimate powers as to deny them all relevancy in universal affairs, as to annihilate their motives at one blow, will be even more unpopular than pessimism. Better face the enemy than the eternal Void! This is why materialism will always fail of universal adoption, however well it may fuse things into an atomistic unity, however clearly it may prophesy the future eternity. For materialism denies 
reality to the objects of almost all the impulses which we most cherish. The real meaning of the impulses, it says, is something which has no emotional interest for us whatever. $(W B, 70-71)$

Now while it is clear that pragmatism's field metaphysics escapes the net of reductive materialism, it is not so evident that it escapes what might be called "effective materialism." By this I mean any view which, while denying that the self and its activities are identical with or reducible to the physicochemical fields to which they are intimately related, also denies that the self and its activities can have any existential reality apart from these specific physicochemical fields.

Such a view, of course, undermines the chief concern of this essay. ${ }^{13}$ It is incumbent upon me to construct a field model of the self that does not exclude the possibility of the self's continuing to exist independently of some of the fields with which it is presently involved. Note that there will be no claim of proving that such an existence is possible. The task is to show that this is an open possibility, thereby allowing for a reasonable "faith," which will have to be supported by grounds other than those that emerge from the analysis and construction of a field-self. I will continue to draw principally upon James and Dewey in the construction of a model of the field-self. Remember, the intention is not to show that either of these thinkers has a fully developed view of the self but rather to utilize often inconsistent aspects of their thought. This means that I may apply their insights and ideas in ways that are not explicit in their texts and that may even in some instances be in opposition to some of their conclusions.

Overall, this will be so in the case of Dewey more than of James. The question of effective materialism is a good example. James, though often inconsistent in details, is surely open to the kind of field-self here suggested, particularly when his thought is considered in all its aspects, including the ethical and the religious. Dewey, on the other hand, will have to be classified as an effective materialist, since he holds "that all the subject-matter of experience is dependent upon physical conditions." 14 Nevertheless, the issue is not as clear-cut and unequivocal as it first appears, and I wish to show that much in Dewey is congenial to a field view of the self in spite of his unsympathetic attitude toward any speculation about immortality.

\section{DEWEY'S RELATIONAL VIEW OF “MIND” AND “MATTER”}

Dewey gives two closely connected reasons as to why he did "not come out frankly and use the word materialism." Together, they are a succinct expression of his more developed relational view of "mind" and "matter." His first reason for rejecting the label of materialism is that philosophies so designated posit a metaphysical view of substance in which matter is a substance and "the only substance." Since Dewey rejects all modes of metaphysical substantialism, he also rejects materialism as a mode of substantialism. 
Dewey's second reason is but an empirical specification of the first. Materialism is an antithetical position opposing matter to the psychical and mental posited as spiritual. Having abandoned this antithetical perspective, Dewey fails "to see what meaning 'matter' and 'materialism' have for philosophy." He goes on to note that "matter has a definite assignable meaning in physical science. It designates something capable of being expressed in mathematical symbols which are distinguished from those defining energy." The generalizing of this definite meaning of "matter" into the philosophical view of materialism is no more legitimate than "generalizing what is designated as energy in physics into spiritualistic metaphysics." If one employs the term "matter" philosophically, therefore, "this meaning . . . should be to name a functional relation rather than a substance." It would then be appropriate to use the term "matter" as "a name for existential conditions in their function as conditions of all special forms of socio-biotic activities and values" (EKV, 605).

Whatever difficulties this doctrine might pose for the field view of the self; the following text clearly expresses Dewey's rejection of reductionistic materialism.

But recognition that all these activities and values are existentially conditioned-and do not arise out of the blue or out of a separate substance called spirit-is far from constituting materialism in its metaphysical sense. For it is only by setting out from the activities and values in experience just as they are experienced that inquiry can find the clues for discovery of their conditions. Denial that the former are just what they are thus destroys the possibility of ascertaining their conditions so that "materialism" commits suicide. It is quite possible to recognize that everything experienced, no matter how "ideal" and lofty, has its own determinate conditions without getting into that generalization beyond limits which constitute metaphysical materialism. $(E K V, 605)^{15}$

Over a decade earlier, Dewey had presented his ideas on the mind-matter question in his great metaphysical work, Experience and Nature. ${ }^{16}$ This rich, subtle, and complex text does not admit of easy summarization or articulation; my concern is to highlight a few passages that point in the direction of a field metaphysics and a field view of the self. In doing so, of course, I must touch upon and quickly pass over a number of questions and aspects of Dewey's philosophy that merit much fuller treatment. Among these would be the nature and role of "events" in his metaphysics; the question of "meaning"; the importance of "quality"; the distinction between "having" and "knowing" and the allied doctrine that there is no immediate knowledge; and the nature and role of "mind," "matter," "consciousness," "spirit," and the like.

Dewey maintains that the tendency of modern science to substitute "qualitative events" for "the older notion of fixed substances" points "to the idea of matter and mind as significant characters of events presented in different contexts, rather than underlying and ultimate substances" $(E N, \mathrm{xi})$. 
At first glance, it might seem that Dewey is positing "events" as the ultimate constituents of reality, neither mental nor material but becoming so according to the context into which they enter. Such an interpretation would be similar to the "neutral monism" interpretation of James's doctrine of "pure experience" and would be subject to the same criticisms. Again, therefore, I would suggest understanding "events" as fields - as processive-relational realities. For Dewey, such events can be "had" or immediately grasped, but they cannot be "known."17

Nevertheless, by seeing nature as a complex of events, we are kept aware of its processive-relational character and can avoid identifying it with or reducing it to any specific quality. Thus, Dewey tells us, "when nature is viewed as consisting of events rather than substances, it is characterized by histories, that is, by continuity of change proceeding from beginnings to endings" (EN, xi-xiii). Further, "events, being events and not rigid and lumpy substances, are ongoing and hence as such unfinished, incomplete, indeterminate" (EN, 159). ${ }^{18}$

When Dewey comes to describe mind and matter, he assigns both to "the complex of events that constitute nature" $(E N, 75)$. He finds "the notion that the universe is split into two separate and disconnected realms of existence, one psychical and the other physical . . . the acme of incredibility" (EN, 267-68). If one begins with the assumption that mind and matter are "two separate things," then one has the task of restoring the connection between them. Both "mechanistic metaphysics" and "spiritualistic metaphysics" begin with this assumption, though they account for the restoration in diametrically opposite ways. For the former, the "cause" that accounts for the other's existence is "matter"; for the latter, it is "mind." In both instances there is "a breach in the continuity of historic process," which can be avoided by simply observing such processes as "growth from infancy to maturity, or the development of a melodic theme" (EN, 273-74). It is the notion of growth, according to Dewey, that enables one "to detect the fallacy in both views."

The reality is the growth-process itself; childhood and adulthood are phases of a continuity, in which just because it is a history, the latter cannot exist until the earlier exists ("mechanistic materialism" in germ); and in which the later makes use of the registered and cumulative outcome of the earlier-or, more strictly, is its utilization ("spiritualistic teleology" in germ). The real existence is the history in its entirety, the history as just what it is. $(E N, 275)$

In stressing the processive character of reality, Dewey is not affirming a doctrine of chaotic, undifferentiated flux. We can distinguish and differentiate realities and aspects of realities on the bases of "rates of change" and breadth of connections or relations. Not all processes change or proceed at the same rate. "The rate of change of some things is so slow, or is so rhythmic, that these changes have all the advantages of stability in dealing with 
more transitory and irregular happenings" (EN, 71). ${ }^{19}$ Dewey finds it a mark of "sound practical sense" when the slower and regular events are designated "structure" and the more rapid and irregular ones "process." But this is a "relational and functional distinction" that both spiritualistic idealism and materialism treat "as something fixed and absolute. One doctrine finds structure in a framework of ideal forms, the other finds it in matter" (EN, 71-72).

Just as "structure" and "process" are differentiated on the basis of a "relational and functional distinction," so are "mind" and "matter." Dewey, along with a number of other contemporary thinkers, has called attention to the misleading feature of language whereby we are led to posit substantive things or entities wherever we encounter nouns: "It is a plausible prediction that if there were an interdict placed for a generation upon the use of mind, matter, consciousness as nouns, and we were obliged to employ adjectives and adverbs, conscious and consciously, mental and mentally, material and physically, we should find many of our problems much simplified" (EN, 75).

Note that Dewey does not claim that our problems would be "solved" by a mere shift in terminology but that they would be "much simplified." We might at least avoid a number of dead-end "solutions" which, while giving us a kind of abstract coherence or rationality, divert our attention and energies from the more concrete experiential aspects of reality. I have suggested that such refocusing is a definite fruit of describing reality in terms of fields, of processive-relational complexes, rather than in terms of essentially different "things" or orders of being, and this is the direction of Dewey's reflections on mind and matter.

Dewey urges us to think "of both mind and matter as different characters of natural events, in which matter expresses their sequential order, and mind the order of their meanings in their logical connections and dependencies" $(E N, 74) .{ }^{20}$ Again, we must avoid thinking of "natural events" as the ultimate, irreducible constituents of reality that combine in different ways called "mind" and "matter." Recall the point made earlier concerning "fields": namely, that you do not have "processes" and "relations" that combine to make a field, but rather that all processes are relational and all relations are processive. This processive-relational or field view is evident, I believe, in the following analogy:

The "matter" of materialists and the "spirit" of idealists is a creature similar to the constitution of the United States in the minds of unimaginative persons. Obviously the real constitution is certain basic relationships among the activities of the citizens of the country; it is a property or phase of these processes, so connected with them as to influence their rate and direction of change [italics added]. But by literalists it is often conceived of as something external to them; in itself fixed, a rigid framework to which all changes must accommodate themselves. $(E N, 73)$ 
Dewey rejects the view "that matter, life and mind represent separate kinds of Being," maintaining instead that they are manifestations of "levels of increasing complexity and intimacy of interaction among natural events" $(E N, 261)$. Here again, I think Dewey's doctrine is congenial to and supportive of a metaphysics that describes reality as "fields within fields within fields. . . ." Thus Dewey contends:

While there is no isolated occurrence in nature, yet interaction and connection are not wholesale and homogeneous. Interacting-events have tighter and looser ties, which qualify them with certain beginnings and endings, and which mark them off from other fields of interaction. Such relatively closed fields come into conjunction at times so as to interact with each other, and a critical alteration is effected. A new larger field is formed, in which new energies are released, and to which new qualities appertain. (EN, 271-72)

Dewey goes on to distinguish "three plateaus of such fields," the physical, the living, and the mental. The physical field is constituted by "narrower and more external interactions," which are articulated in "the mathematicalmechanical system discovered by physics." The second level is that of life, which manifests "qualitative differences, like those of plant and animal, lower and higher animal forms." The distinguishing characters of the third plateau are "association, communication, participation." This mental level "is still further internally diversified, consisting of individualities. It is marked throughout its diversities, however, by common properties, which define mind as intellect; possession of and response to meanings" (EN, 272). 21

While each of these levels "having its own characteristic empirical traits has its own categories," Dewey insists that "they are not 'explanatory' categories, as explanation is sometimes understood; they do not designate, that is, the operation of forces as 'causes.' They stick to empirical facts noting and denoting characteristic qualities and consequences peculiar to various levels of interaction" (EN, 272-73). ${ }^{22}$

The field character of Dewey's metaphysics is also implicit in his notion "that a higher organism acts with reference to a spread-out environment as a single situation." The crucial point being emphasized is that an organism acts with reference to a temporal spread as well as a spatial spread. "Thus an environment both extensive and enduring is immediately implicated in present behavior. Operatively speaking, the remote and the past are 'in' behavior making it what it is. The action called 'organic' is not just that of internal structures; it is an integration of organic-environmental connections" (EN, 279). ${ }^{23}$ To express this in field language, we might say that an organism is constituted by and through participation in a diversity of fields varying in complexity and spatial and temporal scope, overlapping and shading into each other. The continuing intellectual task is the delineation of these fields in terms of their distinctive characteristics, activities, and relations without 
losing sight of the concrete and unique situation that they constitute. This, of course, is an open-ended task that becomes increasingly tentative as we focus on wider and more complex fields, such as human selves.

We might cite Dewey's distinction between "mind" and "consciousness" as an example of delineating fields of different spread and scope.

Mind denotes the whole system of meanings as they are embodied in the workings of organic life; consciousness in a being with language denotes awareness or perception of meanings; it is the perception of meanings; it is the perception of actual events, whether past, contemporary or future, in their meanings, the having of actual ideas. The greater part of mind is only implicit in any conscious act or state; the field of mind-of operative meanings-is enormously wider than that of consciousness. Mind is contextual and persistent; consciousness is focal and transitive. Mind is, so to speak; structural, substantial; a constant background and foreground; perceptive consciousness is process, a series of heres and nows. $(E N, 303)^{24}$

Of course, Dewey does not mean by this last sentence that mind is a static structure related to a processive consciousness. Bearing in mind the "functional and relational distinction" previously made between "structure" and "process," we might say that mind is a field characterized by a slower process and a wider and more numerous set of relations in comparison with the processes and relations that characterize the field of consciousness.

To illustrate the relation between mind and consciousness, Dewey asks us to reflect upon what happens when we read a book. In our reading we are immediately conscious of meanings that come to be and pass away; these existential meanings Dewey calls ideas. We are able to have such ideas, however, only "because of an organized system of meanings of which we are not at any time completely aware." Our ideas or particular apprehensions, then, are possessed and determined by systems of meaning, examples of which would be "mathematical mind" or "political mind." There is, Dewey concludes, a continuum or spectrum between these containing systems "and the meanings which, being focal and urgent, are the ideas of the moment." Dewey faults the "orthodox psychological tradition" for "its exclusive preoccupation with sharp focalization to the neglect of the vague shading off from the foci into a field of increasing dimness" (EN, 305). He later gives the following description of the concrete situation:

If we consider the entire field from bright focus through the fore-conscious, the "fringe," to what is dim, sub-conscious "feeling," the focus corresponds to the point of imminent need, of urgency; the "fringe" corresponds to things that have just been reacted to or that will soon require to be looked after, while the remote outlying field corresponds to what does not have to be modified, and 'which may be dependably counted upon in dealing with imminent need. $(E N, 311)^{25}$

One final text, from Human Nature and Conduct, will serve to illustrate how radical and pervasive was Dewey's processive-relational doctrine of 
mind. He points out that we cannot but be perplexed "by the problem of how a common mind, common ways of feeling and believing and purposing, comes into existence," assuming that "we start with the traditional notion of mind as something complete in itself." This would mean that we have a multiplicity of essentially independent minds, and we must then account for the fact that they realize the character of "commonness" or shared perspective and feeling.

The case is quite otherwise if we recognize that in any case we must start with a grouped action, that is, with some fairly settled system of interaction among individuals. The problem of origin and development of the various groupings, or definite customs, in existence at any particular time in any particular place is not solved by reference to psychic causes, elements, forces. It is to be solved by reference to facts of action, demand for food, for houses, for a mate, for someone to talk to and listen to one talk, for control of others. ${ }^{26}$

Processes and relations, therefore, are not realities added on to separate individual minds, thereby bringing them together in a loosely federated common mind. Rather, processes and relations are the constitutive factors present from the beginning of the emergence of any mind. Thus minds are formed transactionally and always involve concrete environmental factors in their formation. Shared perspectives, customs, feelings, and values are to be expected, then, since the minds that share them come to be and develop through the transactional emergence of these perspectives, customs, feelings, and values. A mind isolated from or completely independent of such features is an empty abstraction. I will later address the question of whether a field view that excludes the possibility of any isolated mind or self also excludes the possibility of any individual mind or self. 